\title{
Screening of priority pollutants in urban stormwater: innovative methodology
}

\author{
S. Zgheib ${ }^{1}$, R. Moilleron ${ }^{2}$ \& G. Chebbo ${ }^{1,3}$ \\ ${ }^{1}$ Université Paris-Est, Cereve, \\ UMR-MA102 Ecole Nationale des Ponts et Chaussées, \\ AgroParisTech, France \\ ${ }^{2}$ Université Paris-Est, Cereve, UMR-MA102 Université Paris 12, \\ AgroParisTech, France \\ ${ }^{3}$ Faculté de Génie, Université Libanaise, Lebanon
}

\begin{abstract}
The implementation of the Water Framework Directive (WFD) 2000/60/CE requires Member States to gain a better understanding of priority pollutants entering surfaces waters. All kinds of effluents as well as urban water (wastewater and stormwater) are concerned. So, studies have put the light on direct discharges of these substances to the aquatic environment, since hazardous pollutants, listed or not in the WFD, could be released to a watercourse by stormwater. Moreover, data about priority substances in urban stormwater are scarce so far worldwide. Till now, monitoring of priority pollutants usually referred to analyses carried out on bulk samples without any discrimination between dissolved and particulate phases. This paper describes an innovative methodology which allows not only the determination of contamination level in both the dissolved and particulate phases of hazardous pollutants, but also all the precautions that must be taken from sampling to analysis. In order to include specific urban pollutants, the WFD list of 33 priority pollutants was scientifically extended to 88 individual substances. All samples will be collected, and monitored for these urban pollutants, by automatic samplers from three storm drainage systems in Paris and its suburb, whose watershed land use differs.
\end{abstract}

Keywords: dissolved phase, particulate phase, priority pollutants, runoff, urban catchments, water framework directive, wastewater. 


\section{Introduction}

The relationship between the environment and the development was one of the most important issues of the $\mathrm{XX}^{\text {th }}$ century and still remain one for the $\mathrm{XXI}^{\mathrm{st}}$. Over the last decades, urbanization within a watershed affect the water cycle by increasing of the impervious surface runoff including rooftops, pavement, roads, driveways and parking lots and by decreasing, during the rain event, the volume of infiltrating water. As a result, runoff is contaminated by pollutants accumulated, during the dry weather period, on impervious urban surfaces. Besides, many substances were introduced in both building and manufactured products (to increase their resistance to fire, to corrosion, etc.), which were judged afterwards as pollutants due to their toxicity, their bioaccumulation and their persistence in the environment. After a storm, these pollutants can leach from those materials. In general, stormwater ends up in watercourses, after a more or less stay into sewers. This represents a potential source of non-point pollution in urban areas.

In urban areas, there are three types of sewers: sanitary or separate sewers, storm sewers and combined sewers. Each of these types has specific properties related to sewer processes. Sanitary sewers collect and transport wastewater from residential and/or commercial areas and industries. The residence time in these sewers is linked to the flowing velocity of wastewater (flow is controlled either by gravity or pressure) and the distance from the end-of-pipe wastewater treatment plant. As a consequence, the longer the residence time, the most important in-sewer chemical and microbial processes. While, in storm sewer networks, water originates from impervious surfaces or semipervious. The residence time of water in such sewer network is quite short. Hence in-sewer chemical and microbial processes are of less importance. More and more, stormwater becomes a crucial issue and an improved knowledge of its contamination is required.

Furthermore, the European Water Framework Directive (WFD) 2000/60/CE, whose main objective is to achieve a "good chemical status" for all the water bodies, requires Member States to gain a better understanding of priority substances entering surfaces waters. Indeed, the decision $n^{\circ} 2455 / 2001 / E C$ of the European Parliament and Council puts the light on a list of 33 priority substances that must be reduced by 2015 or eliminated by 2020 for dangerous substances. The choice of these substances was relevant with respect to their specific industrial sources since they were identified using the COMMPS approach (Combined Monitoring-based and Modelling-based Priority Setting). Due to the pollution that could be brought by industrial, agricultural and urban areas; all kinds of these effluents are concerned and shall be investigated to determine their level of contamination by these priority pollutants. Additionally, the WFD primarily focused on the water phase. This is its main limitation, since the distribution of the contaminants between the water and/or solid phases in stormwater, is needed for an optimisation of the best management practices.

As a consequence, this research focuses on stormwater. One of the interesting features of our work is to extend the list of studied pollutants in order to include 
those specific to urban stormwater. Besides, an innovative screening methodology for urban samples (stormwater, runoff, wastewater and combined wet weather flow) for separate analyses of the dissolved and the particulate phases will be described with all the precautions that must be taken from sampling to analysis.

This research is performed within the framework of the third phase of the OPUR (Observatory of Urban Pollutants) research programme, which aimed at improving knowledge of the origin, the characteristics and the transfer of pollutants in urban catchments during dry and wet weather.

\section{Choice of urban pollutants}

During a rain event, the stormwater quality as well as the load of contaminants is affected by the types of impervious surfaces, on which runoff occurs and from the atmospheric component. Indeed, in bulk atmospheric deposition, contaminants originate both from wet processes and dry settling. During precipitation, contaminants may be removed from air by either rain-in or washout (Gill and Graedel [1]). As a consequence, a large number of constituents, both organic and inorganic, may be present in stormwater (Eriksson et al [2]), wastewater or even in runoff (Garnaud [3], Gromaire-Mertz et al [4], Allen Burton and Pitt [5]). The measured concentrations may vary from event to event and from site to site (Gromaire-Mertz et al [4]), underlying the unique sitespecific conditions affecting receiving water impacts. In 1976, a first list (Directive 76/464/EEC) of pollutants was established by European Union (EU) on pollutants that caused pollution into the aquatic environment of the Community. Then in 2000, the EU has established a list for priority substances in the water policy field, for which quality standards and measurements for the emission controls reduction will be set at Community level. 33 priority substances have been identified and are listed in the annex X of the WFD. Eriksson et al [6] have established a new list of pollutants to provide a clear statement on the need tackle of non-point source pollution in urban areas. This list gives valuable support for stormwater managers regarding the comparison of various stormwater management strategies. It was based on a theoretically assessment of the stormwater pollutants presence called the CHIAT (Chemical Hazard Identification and Assessment Tool) methodology (Eriksson et al [6]). It was developed within the European $5^{\text {th }}$ Framework Project named Daywater (Thévenot and Förster [7]) to develop an adaptation decision support system for integration of stormwater source control into sustainable urban water management strategies to support stormwater managers. However, these selected stormwater priority pollutants (SSPPs) have not been yet experimentally screened on stormwater samples.

Moreover, a number of studies have linked specific pollutants in stormwater runoff with their sources (Allen Burton and Pitt [5]). So, in order to characterize the different types of water found in urban environment, after a literature review on monitoring programs and sources of urban pollutants, we established a new list including ordinary water quality parameters (to evaluate the general 
pollution), but also other chemical substances that should be monitored to prevent any future problems of pollution with respect to their urban sources. The urban sources considered at the scale of a rain event in this paper are: atmospheric deposits, traffic, gardens and buildings (table 1).

Table 1: $\quad$ Sources of the pollutants in urban areas.

\begin{tabular}{|l|l|l|l|}
\hline \multicolumn{1}{|c|}{ Atmosphere deposits } & \multicolumn{1}{c|}{ Traffic } & \multicolumn{1}{c|}{ Buildings } & \multicolumn{1}{c|}{ Gardens } \\
\hline - organic substances (such as HAPs, & -metals $(\mathrm{Zn}$, & - metals, & pesticides and \\
PCBs, pesticides \& alkylphenols) & $\mathrm{Cu}, \mathrm{Pb}, \mathrm{Pt}, \mathrm{Cd})$, & - nonylphenols, & their additives \\
- volatiles substances (BTEX \& & -alkylphenols, & - PBDEs & (alkylphenols, \\
COHV) & - HAPs & - phtalates & organotins) \\
- flame retardants (PBDEs, PCBs, & & & \\
chloroalkanes) & & & \\
\hline
\end{tabular}

To resume these latter substances were chosen among: the WFD list of 33 priority substances, the directive 76/464/EEC and the SSPPs list (Eriksson et al [6]). We have enlarged some chemical families of pollutants to include those deriving from urban areas. While, the pharmaceuticals and personal care products (PPCPs), which refer to prescription and over-the-counter therapeutic drugs, veterinary drugs, fragrances and cosmetics, were purposely excluded from our work. As a result, a list of 88 substances, from 13 different chemical families, has been established as follows, including:

- Ordinary water quality parameters: temperature, $\mathrm{pH}$, conductivity, total nitrogen (TKN), total phosphorus (TP), suspended solids (SS) and chemical oxygen demand (COD),

- $\quad 8$ metals: cadmium, lead, mercury, nickel, platinum, chromium, copper and zinc,

- $\quad 3$ organotins: tributyltin, dibutyltin and monobutyltin,

- 6 PAH of the US EPA (Environmental Protection Agency) priority list,

- 8 PCBs: PCB28, PCB52, PCB101, PCB118, PCB138, PCB153, PCB180 and PCB194,

- 5 chlorobenzenes: hexachlorobenzene, pentachlorobenzene, 1,2,4trichloro-benzene, 1,2,3-trichlorobenzene and 1,3,5-trichlorobenzene,

- 4 BTEX: Benzene, Ethylbenzene, Isopropylbenzene, Toluene and Xylenes,

- 7 Volatiles organics compounds (VOCs): 1,2-dichloroethane, methylene chloride, hexachlorobutadiene, chloroform, carbon tetrachloride, tetrachloroethylene and trichloroethylene,

- 2 chlorophenols: pentachlorophenol and 4-chloro-3-methylphenol,

- 5 alkylphenols: nonylphenols, 4-(para)-nonylphenol, para-tertoctylphenol, 4-n-octylphenol and 4-tert-butylphenol,

- 3 PBDEs: pentabromodiphenylether, octabromodiphenylether and decabromodiphenylether,

24 pesticides: alachlor, aldrin, endrin, dieldrin, DDT-2,4', DDT-4,4', isodrin, endosulfan (alpha \& beta), lindane, alpha hexachlorocyclohexane, chlorfen-vinphos, chlorpyrifos, trifluralin, atrazine, desethylatrazine, 
desethylsimazine, simazine, diuron, isoproturon, metaldehyde, aminotriazole, glyphosate and AMPA,

- C10-C13 chloroalkanes,

- $\quad$ Phthalates: DEHP.

However, data about priority substances in stormwater remain scarce so far worldwide. In fact, the scientific literature within this field has focused on quality parameters (Kafi-Benyahia et al [8]), heavy metals (Garnaud et al [9], Davis et al [10], Herngren et al [11], Sabin et al [12], Rule et al [13]), polycyclic aromatic hydrocarbons (PAHs) (Polkowska et al [14], Ngabe et al [15]), or on a given family of priority substances (PBDEs for Kierkegaard et al [16] and Wang et al [17], organotins for Berto et al [18], alkylphenols for Remberger et al [19], Fries and Puttmann [20]). Only a few surveys deal with all the substances of the priority list on bulk samples of wastewater or runoff for Rule et al [21,22]. For many organic substances of our list there is no information available about the concentrations in both the dissolved and the particulate phases in the urban environment.

\section{Screening methodology}

\subsection{Generalization of the distinction between particulate and dissolved phases}

A recent survey about French reference analytical methods used by certified laboratories (Coquery et al [23]) underlined that among the fifty methods available to achieve the priority substances analysis only 12 mentioned the suspended solids (SS). However, that does not mean they allow their characterization, since only 5 developed a specific protocol to remove SS to finally analyse the sole dissolved phase. The 38 remaining deal with the bulk sample. Coquery et al [23] also noticed that those methods are applicable only for waters with SS levels below $50 \mathrm{mg} / 1$ and specify that interferences are higher in the presence of organic matter, SS and colloids, which can increase limits of detection. Nevertheless, no recommendation is given for the treatment of waters with a SS level above this limit. Additionally, the monitoring of the WFD priority substances has been entrusted to the French National Institute for Industrial Environment and Risks (INERIS), the first results showed that SS were taken into account by certified laboratories when they were above 500 $\mathrm{mg} / \mathrm{l}$. In that case, after filtration, analysis was carried out on both the particulate and the dissolved phases. In most cases, analyses were made on bulk water sample without any specific analyses on suspended solids.

When analyses are performed on bulk samples, it can generate misinterpretation of the results because:

- $\quad$ Analyses carried out on unfiltered samples will provide poor-quality data with regard to the representativity of the contamination in water and also poor comparability between data from different laboratories (Coquery et al [23]),

- For organic pollutants having $\log \mathrm{Kp}>3$, their concentration should preferably be measured in SS rather than in the bulk water sample or dissolved 
phase. As a matter of fact, solvent extraction of bulk water samples with high SS concentrations will be much less efficient for those substances than if performed on the SS itself, using extraction methods designed for solid phases, such as sediment or soil (Coquery et al [23]).

So, the results of dissolved and SS pollutant concentrations should be given separately, as such data are often lacking from monitoring databanks. These pose some interesting challenges for analytical testing laboratories:

- Water samples with low SS concentrations need large volumes, up to 10 litres to be filtered to get a suitable mass to perform reproducible analyses on solids,

- In some cases, analytical methods have not been fully validated for the solid phase in certified laboratories whereas they are analysed in routine in research laboratories.

So this research attempt at performing a whole screening of the 88 listed pollutants on different types of urban waters such as stormwater, wastewater and runoff water on dissolved and particulate matter. For samples with low SS, large volume of water samples, (i.e., 24 litres) will be filtrated to collect enough particles for analyses. Finally, in order to compare the analyses on both dissolved and particulate phases to the current analyses (i.e., on bulk samples), these two procedures will be carried out on the same sample.

\subsection{Sampling procedure}

In this research, ordinary water quality parameters, organics and minerals pollutants are analysed on each sample. For this reason, two different refrigerated automatic water samplers $\left(+4^{\circ} \mathrm{C}\right)$ are used to preserve sample integrity, as shown in table 2 . They collect water at the outlet of each watershed. They were programmed to provide a mean rain event sample. They allow collecting $12 \times 1$ litre samples. They are equipped with two types of containers to avoid any contamination. Hence, for organic pollutants, samples are collected in Pyrex amber glass bottles with Teflon sampling tubes. Glassware is previously thoroughly washed with TFD4 (a detergent), to remove any trace of organic contamination, then rinsed with deionised water and finally heated at $500^{\circ} \mathrm{C}$ prior to use. Furthermore, for minerals substances and ordinary water quality parameters, samples were collected in polyethylene (PE) bottles with PVC tubes. To avoid any metallic contamination, bottles are cleaned according to the following method: $24 \mathrm{~h}$ in a detergent bath (Extran, 5\%), to remove any organic traces, then $24 \mathrm{~h}$ in a nitric acid (5\%, Normatom) bath and finally $24 \mathrm{~h}$ in another nitric acid (5\%, Normatom) bath. Between all bathes, bottles are rinsed with ultra-pure water (MilliQ system, Millipore).

Table 2: $\quad$ Sampling procedure for urban pollutants screening.

\begin{tabular}{|l|l|l|l|}
\hline & Organic compounds & Mineral compounds & Basic parameters \\
\hline Phase considered & Bulk sample, dissolved and particulate phases & Bulk sample \\
\hline Sampling procedure & -1 automatic sampler & -1 automatic sampler & \\
& $-121-1$ glass bottles & $-121-1$ PE bottles & \\
& - Teflon tubes & - PVC tubes & \\
& $-4^{\circ} \mathrm{C}$ & $-4^{\circ} \mathrm{C}$ & \\
\hline
\end{tabular}


Bulk samples are taken from three different storm sewers presenting different land use covers: a residential area in the suburb of Paris [Sucy-en-brie: $2.61 \mathrm{~km}^{2}$, with an impervious surface coefficient (ISC) of 0.27], two urban areas, one in Paris centre [Tolbiac: $1.30 \mathrm{~km}^{2}$, ICS 0.80], and another in the suburb of Paris [Noisy-le-Grand (Centre urbain): $2.30 \mathrm{~km}^{2}$, ICS 0.65] as shown in fig. 1. Data from Meteo-France are used to gauge the sampling frequency in order to catch the whole rain event. At all sampling sites, flow measurements are made using ultrasonic transit time flowmeter capable of accurate measurement of depth and velocity in sewers.
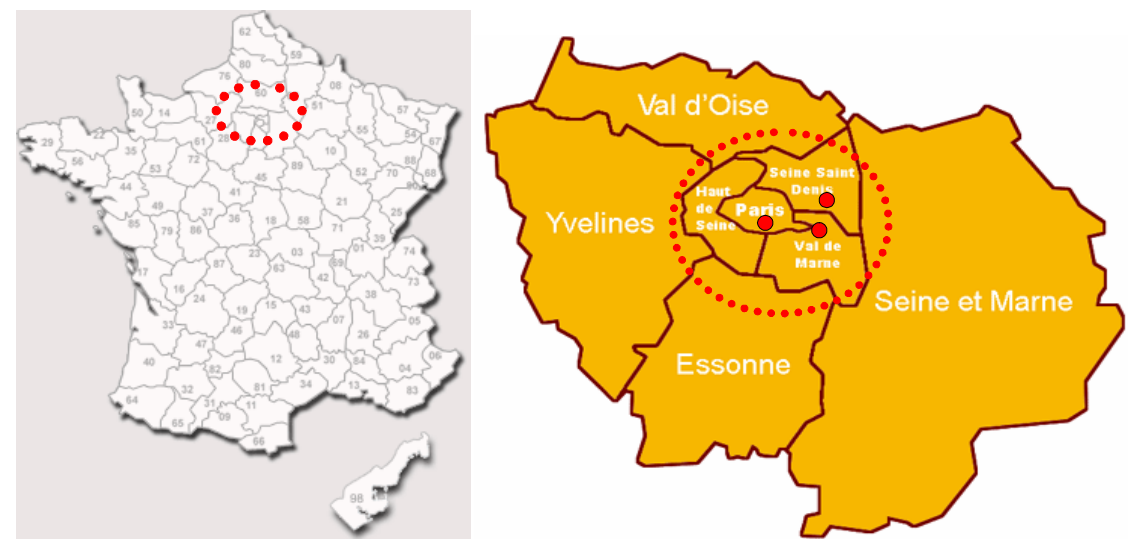

Figure 1: Location of experimental sites in Paris centre and its suburb.

\subsection{Analytical procedure}

All the analyses are carried out by a certified laboratory that complies with specifications we wrote to ensure the determination of the level of contamination of both the particulate and the dissolved phase. This laboratory has been chosen among 10 laboratories that answered our specifications. On each site a specific campaign will be carried out to compare the level of contamination got from the analysis of the bulk sample on one hand, and from the analysis of the dissolved and the particulate phases, on the other hand.

Once the samples are fetched after a rain event, the first step consists in mixing all the bottles to get a mean sample of the event. Afterwards, bulk samples are filtered with a succession of $90-\mathrm{mm}$ pre-combusted filters from $2.7 \mu \mathrm{m}(\mathrm{GF} / \mathrm{D}$, Whatman) to $0.7 \mu \mathrm{m}(\mathrm{GF} / \mathrm{F}$, Whatman), in a glass filtration unit in order to get the dissolved phase for organic contaminants. This latter is sent to the certified laboratory for analysis within 24 hours. Filters with suspended solids are deep-frozen at $-28^{\circ} \mathrm{C}$, then lyophilized and stored at $4{ }^{\circ} \mathrm{C}$ prior to analysis, fig. 2 .

The analytical procedures used by the laboratory follow the existing French (AFNOR) or international (ISO) standards. When no standard was available, the laboratory has developed and validated its own methods. During analysis and in 
case where other substances are identified we will attempt to quantify them. Ordinary water quality parameters are measured on the bulk samples.

In addition, field blanks will be done on automatic water samplers and on the whole analytical procedure.

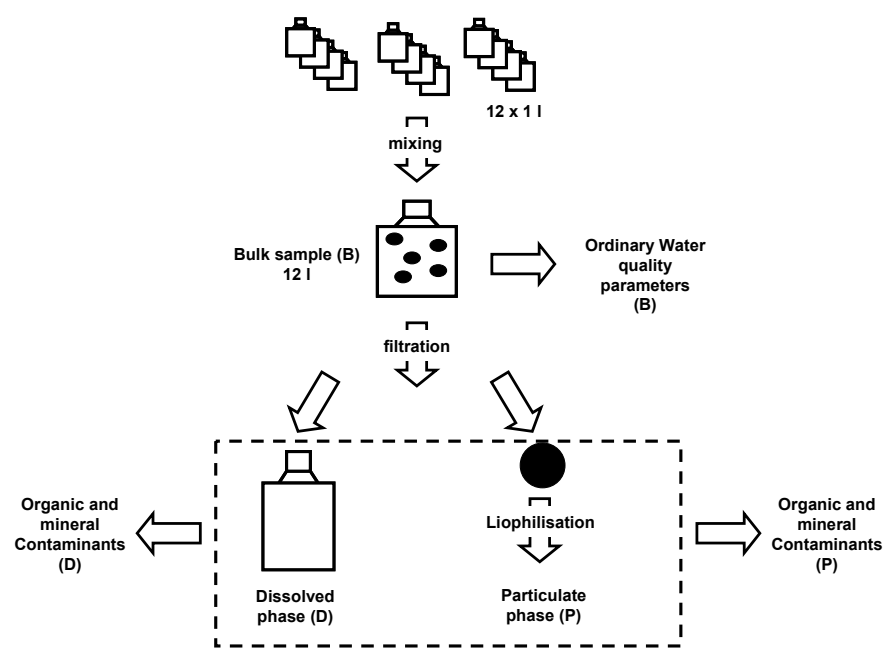

Figure 2: $\quad$ Analytical methodology for urban pollutants screening.

\section{Conclusion}

This paper describes an innovative methodology to screen urban pollutants in storm sewers. So, the proposed methodology aimed at quantifying, for the first time, a list of 88 pollutants in both the dissolved and the particulate phases for urban water with a detailed description of precautions to avoid any biased sample concentration. This methodology can be applied on different types of water samples such as stormwater and wastewater from combined sewers collected at the outlet of urban watersheds, but also runoff from the different types of urban surfaces. In a first attempt, stormwater from three different storm sewers will be investigated followed by wastewater and runoff. So, this research will provide the fist database concentrations for the 88 pollutants in dissolved and particulate phases for different kind of urban water samples collected from sites with different land uses pattern.

\section{Acknowledgements}

The authors gratefully acknowledge the Seine-Normandy Water Agency (AESN), the Interdepartmental Association for Sewage Disposal in Paris Conurbation (SIAAP), the Municipality of Paris, the Water and Sewage Disposal Departmental Administrations of Seine Saint Denis (DEA93), the Water and Sewage Disposal Departmental Administration of Val de Marne (DSEA94) and 
Regional Council of "Ile de France" (CRIF) for their financial support within the framework of the OPUR programme research.

\section{References}

[1] Gill, P.S. and Graedel, T.E., Organic films on atmospheric aerosol particles, fog droplets, cloud droplets, rain drops and snowflakes. Rev Geophys Space Phys21.p. 903-920, 1983.

[2] Eriksson, E., Auffarth, K., Henze, M., and Ledin, A., Characteristics of grey wastewater. Urban Water. 4(1), p. 85-104, 2002.

[3] Garnaud, S., Transfert et évolution géochimique de la pollution métallique en bassin versant urbain, Ecole Nationale des Ponts et Chaussées. p. 396p., 1999.

[4] Gromaire-Mertz, M.C., Garnaud, S., Gonzalez, A., and Chebbo, G., Characterisation of urban runoff pollution in Paris. Water Science and Technology. 39(2), p. 1-8, 1999.

[5] Allen Burton, G.J. and Pitt, R.E., Stormwater Effects Handbook: A Toolbox for Watershed Managers, Scientists, and Engineers, ed. L. Publishers. 929, 2001.

[6] Eriksson, E., Baun, A., Scholes, L., Ledin, A., Ahlman, S., Revitt, M., Noutsopoulos, C., and Mikkelsen, P.S., Selected stormwater priority pollutants - a European perspective. Science of The Total Environment. 383(1-3), p. 41-51, 2007.

[7] Thévenot, D.R. and Förster, M. Developing the daywater adaptive decision support system for urban stormwater source control: a challenge! in 10th International Conference on Urban DrainageCopenhagen/Denemark, 2005.

[8] Kafi-Benyahia, M., Gasperi, J., Moilleron, R., Gromaire-Mertz, M.C., and Chebbo, G., Spatial variability of the characteristics of combined wet weather pollutant loads in Paris. Water Research. 42(3), p. 539-549, 2008.

[9] Garnaud, S., Mouchel, J.-M., Chebbo, G., and Thevenot, D.R., Heavy metal concentrations in dry and wet atmospheric deposits in Paris district: comparison with urban runoff. The Science of The Total Environment. 235(1-3), p. 235-245, 1999.

[10] Davis, A.P., Shokouhian, M., and Ni, S., Loading estimates of lead, copper, cadmium, and zinc in urban runoff from specific sources. Chemosphere. 44(5), p. 997-1009, 2001.

[11] Herngren, L., Goonetilleke, A., and Ayoko, G.A., Understanding heavy metal and suspended solids relationships in urban stormwater using simulated rainfall. Journal of Environmental Management. 76(2), p. 149$158,2005$.

[12] Sabin, L.D., Lim, J.H., Stolzenbach, K.D., and Schiff, K.C., Contribution of trace metals from atmospheric deposition to stormwater runoff in a small impervious urban catchment. Water Research. 39(16), p. 3929-3937, 2005. 
[13] Rule, K.L., Comber, S.D.W., Ross, D., Thornton, A., Makropoulos, C.K., and Rautiu, R., Diffuse sources of heavy metals entering an urban wastewater catchment. Chemosphere. 63(1), p. 64-72, 2006.

[14] Polkowska, Z., Kot, A., Wiergowski, M., Wolska, L., Wolowska, K., and Namiesnik, J., Organic pollutants in precipitation: determination of pesticides and polycyclic aromatic hydrocarbons in Gdansk, Poland. Atmospheric Environment. 34(8), p. 1233-1245, 2000.

[15] Ngabe, B., Bidleman, T.F., and Scott, G.I., Polycyclic aromatic hydrocarbons in storm runoff from urban and coastal South Carolina. The Science of The Total Environment. 255(1-3), p. 1-9, 2000.

[16] Kierkegaard, A., Bignert, A., Sellstrom, U., Olsson, M., Asplund, L., Jansson, B., and de Wit, C.A., Polybrominated diphenyl ethers (PBDEs) and their methoxylated derivatives in pike from Swedish waters with emphasis on temporal trends, 1967-2000. Environmental Pollution. 130(2), p. 187-198, 2004.

[17] Wang, Y., Zhang, Q., Lv, J., Li, A., Liu, H., Li, G., and Jiang, G., Polybrominated diphenyl ethers and organochlorine pesticides in sewage sludge of wastewater treatment plants in China. Chemosphere. 68(9), p. 1683-1691, 2007.

[18] Berto, D., Giani, M., Boscolo, R., Covelli, S., Giovanardi, O., Massironi, M., and Grassia, L., Organotins (TBT and DBT) in water, sediments, and gastropods of the southern Venice lagoon (Italy). Marine Pollution Bulletin Measuring and Managing Changes in Estuaries and Lagoons. 55(10-12), p. 425-435, 2007.

[19] Remberger M., Kaj L., Palm A., Sternbeck J., Kvernes E., and E., B.-L., Screening tertiary butylphenols, and long-chain alkylphenols in the Swedish environment, in Report, IVL Swedish Environmental Research Institute. p. 1-93, 2003.

[20] Fries, E. and Puttmann, W., Occurrence of 4-Nonylphenol in rain and snow. Atmospheric Environment. 38(13), p. 2013-2016, 2004.

[21] Rule, K.L., Comber, S.D.W., Ross, D., Thornton, A., Markropoulos, C.K., and Rautiu, R., Survey of priority substances entering thirty English wastewater treatment works. Water and Environment Journal. 20, p. 177184, 2006.

[22] Rule, K.L., Comber, S.D.W., Ross, D., Thornton, A., Makropoulos, C.K., and Rautiu, R., Sources of priority substances entering an urban wastewater catchment--trace organic chemicals. Chemosphere. 63(4), p. 581-591, 2006.

[23] Coquery, M., Morin, A., Becue, A., and Lepot, B., Priority substances of the European Water Framework Directive: analytical challenges in monitoring water quality. TrAC Trends in Analytical Chemistry. 24(2), p. 117-127, 2005. 